\title{
Pseudoporphyria induced by hemodialysis
}

\author{
Beata Bergler-Czop, Ligia Brzezińska-Wcisło \\ Department of Dermatology, Silesian Medical University, Katowice, Poland \\ Head of Department: Prof. Ligia Brzezińska-Wcisło MD, PhD
}

Postep Derm Alergol 2014; XXXI, 1: 53-55

DOI: $10.5114 /$ pdia.2014.40662

\begin{abstract}
Pseudoporphyria is a condition identical to porphyria cutanea tarda (PCT) on clinical and histological grounds, but without any biochemical porphyrin abnormality. Excessive sunlight and UVA exposure (for example tanning beds), drugs such as: non-steroidal anti-inflammatory drugs, retinoids, antibiotics, diuretics and others are supposed to be etiological factors of pseudoporphyria. Cases of PCT and pseudoporphyria in patients with HCV infection and hemodialysed due to chronic renal failure were also described. Here, we describe a clinical case of a 57-year-old patient, who developed cutaneous changes on the face and the dorsal surfaces of hands clinically and histologically characteristic of PCT but with normal levels of urine porphyrins.
\end{abstract}

Key words: acne vulgaris, etiology, cytokines.

\section{Introduction}

Porphyria cutanea tarda (PCT) is the most common form of disturbances in porphyrin metabolism and it affects uroporphyrinogen decarboxylase - the fourth enzyme in the hem synthesis pathway, which converts uroporphyrinogen III to coproporphyrinogen III.

The most common form of PCT is an acquired one, in which toxic damage to liver caused by alcohol, hepatotoxic drugs, infection with hepatotropic viruses or haemosiderosis becomes an initiating factor. The condition is the most common in men aged 40 to 60 years. Skin changes appear in the form of blisters, erythemas, erosions, scabs and scars in exposed and post-traumatic areas.

The diagnosis of PCT is based on excessive excretion of uro- and coproporphyrin, apart from dermatologic changes. It is also crucial to show a decreased uroporphyrinogen decarboxylase activity in fibroblast and erythrocyte cultures.

Pseudoporphyria is a condition with the clinical and histological image similar to PCT but without disturbances in the levels of porphyrin. The considered etiological factors are: sun exposure, UVA (in solaria), non-steroidal anti-inflammatory drugs, retinoids, antibiotics and diuretics. Pseudoporphyria cases were also described in HCV infection and in patients subjected to chronic hemodialysis due to chronic renal failure [1-3].

\section{Case report}

The patient is 57 years old. First skin changes in the form of erosions and blood-filled blisters on dorsum of hands, fingers, forearms and within temples area appeared 4 years earlier, a year after hemodialyses due to chronic renal insufficiency started, caused by glomerulonephritis. The patient was neither treated or diagnosed for skin changes, nor was he constantly treated for any other condition and he showed no other non-renal chronic conditions.

In 2011, the patient was referred to the Dermatology Clinic of the Silesian Medical University in Katowice for diagnosis with a suspected PCT or pemphigus. At the same time, the patient attended the Nephrology Clinic of the Medical University and he was hemodialysed 3 times a week.

On admittance, multiple, well-formed blisters filled with serous-blood secretion, scabbed erosions, discolourations and scars after healed changes were present on the dorsum of hands, forearms, forehead and temples. Mucosa were free of changes, fingernails were regular, peripheral lymph nodes - not enlarged (Figures 1-3).

Laboratory tests: white blood rate (WBR) 91, creatinine $818 \mathrm{mmol} / \mathrm{l}$, proteinuria and erythrocyturia in general urine test. Others: blood morphology with smear, glucose, iron level, electrolytes, asparagine aminotrans-

Address for correspondence: Beata Bergler-Czop MD, PhD, Department of Dermatology, Silesian Medical University, 20/24 Francuska St, 40-027 Katowice, Poland, phone: +48 501352 033, e-mail: bettina2@tlen.pl

Received: 7.04.2013, accepted: 23.06.2013. 


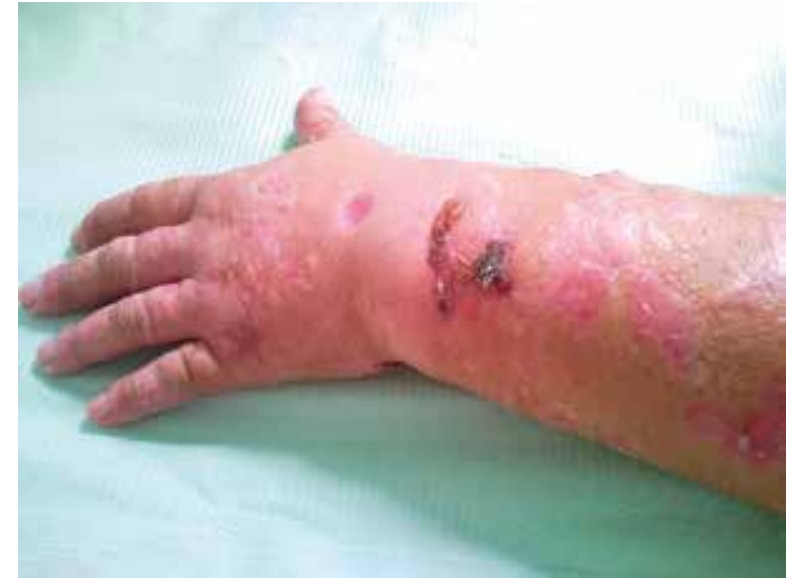

Figure 1. Patient (57 years old), cicatrisation and wellformed blisters on the forearms

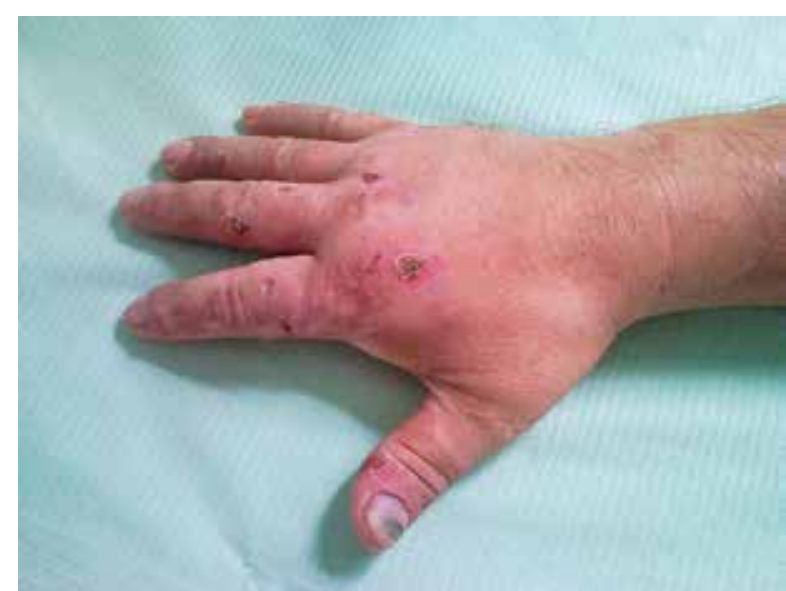

Figure 2. Patient (57 years old), crusts and blisters on the hand

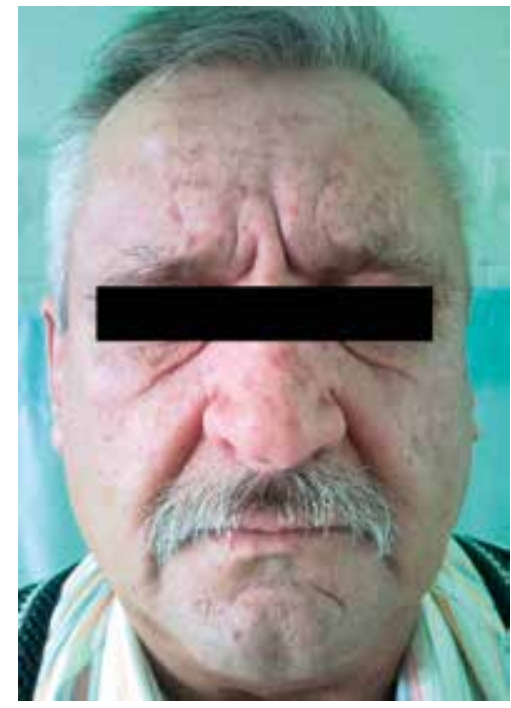

Figure 3. Patient (57 years old), cicatrisation and hyperpigmentation on the face pherase (AST), alanine aminotranspherase (ALT), $\gamma$-glutamylotranspeptidase (GGTP), aldose, protein, protein electrophoresis, creatine phosphokinase (CPK), aldolase, rheumatoid tests (Latex-R, Waaler-Rose's test, ASO) were correct.

Due to too small amount of urine produced by the patient, no tests from a day's urine collection for $\Delta$-aminolevulinic acid and porphobilinogen were performed.

Coproporphyrin levels in urine were regular. Histopathology showed: subepidermal blisters, typical of both pemphigus and porphyria cutanea tarda. No antibodies against basic membrane antigens and pemphigus antibodies were detected using indirect immunofluorescence on monkey and guinea pigs oesophagus.

Nephrological consultation excluded contraindications for possible use of anti-malaria drugs. On the basis of tests and clinical image, we diagnosed a pseudoporphyria during hemodialysis. The patient was prescribed local treatment with antibiotics and steroids and a local improvement was achieved.

At the moment, the patient is under constant control of the Dermatology and Nephrology Clinic. N-acetyl-cysteine is planned to be used at a dose of $2 \times 400 \mathrm{mg}$, according to the literature.

\section{Discussion}

Due to the fact that pseudoporphyria shows a similar clinical and histological image to PCT, this condition is often difficult to diagnose and treat. In our case, the patient was dialysed due to a chronic renal failure. After first skin changes developed, the treatment in the local clinic was only symptomatic. The Dermatology Clinic preliminarily qualified the patient for $\mathrm{N}$-acetyl-cysteine treatment. Nephrological contraindications for possible use of anti-malaria drugs were excluded.

Similarly, El Kabbaj et al. [2] showed a case of a 33-yearold woman, in whom pseudoporphyria developed during hemodialyses. The patient did not respond to the oral treatment with $\mathrm{N}$-acetyl-cysteine. A good response was obtained only after anti-malaria drugs were included. Guiotoku et al. [4] observed a case related with hemodialysis and peritoneal dialysis but authors described a good response of the patient to oral $\mathrm{N}$-acetyl-cysteine treatment. Relations between pseudoporphyria and dialysis were also presented by Felix et al. [5], Pérez et al. [6] and Cooke et al. [7].

Masmoudi et al. [8] performed a retrospective analysis of 363 chronically dialysed patients. The mean dialysis time was 52.4 months. Eighty-eight percent of patients showed skin complications of dialysis. Pseudoporphyria was diagnosed only in 2 patients from the tested group. Massone et al. [9] described a 65-year-old patient dialysed due to a chronic renal failure in Waldenstrom's macroglobulinaemia. The changes in the patient disap- 
peared after the oral treatment with $\mathrm{N}$-acetyl-cysteine and change of membrane in the dialysis machine.

Kochs et al. [3] described 2 patient cases, in whom pseudoporphyria skin changes (clinical and histopathological image of porphyria cutanea tarda, porphyrin levels in serum were regular) appeared after long-term visits in solarium and disappeared after the patients stopped going to the solarium. Timmer-de Mik et al. [10] described a case of pseudoporphyria in a patient, in whom Imatinib was used. Imatinib is a synthetic blocker of a tyrosine kinase, used for treatment of chronic leukaemia. Schmutz et al. [11] and Degiovanni and Darley [12] observed PCTlike changes with regular porphyrin changes in a patient receiving ciprofloxacin. Kwong and Hsu [13], Tolland et al. [14] and Dolan et al. [15] showed a case of pseudoporphyria induced by a second-generation anti-mycotic drug, voriconazol.

Other causes, which may produce pseudoporphyria-like changes are derivatives of phenylpropionic acid, mostly naproxen. Schäd et al. [16] and Werth [17] estimated pseudoporphyria risk factors in children with juvenile arthritis exposed to long-term treatment with naproxen. It has been shown that pseudoporphyria more frequently appears in the group with higher leucocytosis, WBR, lower level of haemoglobin and in the group receiving anti-malaria drugs (possible treatment use in pseudoporphyria!). Changes appeared on average after 2 years of using naproxen. In a 59-year-old woman described by Oh et al. [18], pseudoporphyria changes appeared after phototherapy SUP 311.

Coxibie (COX2 inhibitor, anti-inflammatory drug) caused pseudoporphyria-like skin changes in a patient described by Schmutz et al. [19].

We presented pseudoporphyria in a patient dialysed due to chronic renal failure. Despite literature descriptions, such cases are frequently difficult to diagnose and treat and the effects of treatment often depend on possibilities of eliminating the causes, which was impossible in the case of our patient.

\section{References}

1. Fevang SA, Kroon S, Skadberg Ø. Pseudoporphyria or porphyria cutanea tarda? Diagnostic and treatment difficulties. Acta Derm Venereol 2008; 88: 426-7.

2. El Kabbaj D, Laalou A, Alouane Z, et al. Hemodialysis-associated pseudoporphyria resistant to N-acetylcysteine. Saudi J Kidney Dis Transpl 2011; 22: 311-4.

3. Kochs C, Mühlenstädt E, Neumann NJ, Hanneken S. Solarium-induced pseudoporphyria and variegate porphyria as rare differential diagnoses of porphyria cutanea tarda. Hautarzt 2009; 60: 790-3.

4. Guiotoku MM, Pereira Fde P, Miot HA, Marques ME. Pseudoporphyria induced by dialysis treated with oral N-acetylcysteine. An Bras Dermatol 2011; 86: 383-5.

5. Felix RH, Silva MF Jr, Almeida JB, Neto PB. Pseudoporphyria associated with hemodialysis. Kidney Int 2011; 79: 140.
6. Pérez L, Fernández-Redondo V, Toribio J. Porphyria cutanea tarda in a dialyzed female patient. Actas Dermosifiliogr 2006; 97: 115-7.

7. Cooke NS, McKenna K. A case of haemodialysis-associated pseudoporphyria successfully treated with oral N-acetylcysteine. Clin Exp Dermatol 2007; 32: 64-6.

8. Masmoudi A, Ben Hmida M, Mseddi M, et al. Cutaneous manifestations of chronic hemodialysis. Prospective study of 363 cases. Presse Med 2006; 35: 399-406.

9. Massone C, Ambros-Rudolph CM, Di Stefani A, Müllegger RR. Successful outcome of haemodialysis-induced pseudoporphyria after short-term oral N-acetylcysteine and switch to high-flux technique dialysis. Acta Derm Venereol 2006; 86: 538-40.

10. Timmer-de Mik L, Kardaun SH, Kramer MH, et al. Imatinib-induced pseudoporphyria. Clin Exp Dermatol 2009; 34: 705-7.

11. Schmutz JL, Barbaud A, Tréchot P. Ciprofloxacin and pseudoporphyria. Ann Dermatol Venereol 2008; 135: 804.

12. Degiovanni CV, Darley CR. Pseudoporphyria occurring during a course of ciprofloxacin. Clin Exp Dermatol 2008; 33: 109-10.

13. Kwong WT, Hsu S. Pseudoporphyria associated with voriconazole. J Drugs Dermatol 2007; 6: 1042-4.

14. Tolland JP, McKeown PP, Corbett JR. Voriconazole-induced pseudoporphyria. Photodermatol Photoimmunol Photomed 2007; 23: 29-31.

15. Dolan CK, Hall MA, Blazes DL, Norwood CW. Pseudoporphyria as a result of voriconazole use: a case report. Int J Dermatol 2004; 43: 768-71.

16. Schäd SG, Kraus A, Haubitz I, et al. Early onset pauciarticular arthritis is the major risk factor for naproxen-induced pseudoporphyria in juvenile idiopathic arthritis. Arthritis Res Ther 2007; 9: R10.

17. Werth VP. Dermatology vignette. Pseudoporphyria caused by NSAIDs. J Clin Rheumatol 2001; 7: 123.

18. Oh C, Jones B, Solomon R, Egan CA. Pseudoporphyria secondary to narrowband UVB phototherapy for psoriasis. Australas J Dermatol 2006; 47: 134-6.

19. Schmutz JL, Barbaud A, Tréchot P. Ciprofloxacin and pseudoporphyria. Ann Dermatol Venereol 2008; 135: 804. 